\title{
La participación en la construcción histórica latinoamericana de la Agroecología y sus niveles de territorialidad
}

\author{
Eduardo Sevilla Guzmán \\ Universidad de Córdoba \\ fs1segue@uco.es
}

Recibido: 13-05-2014

Aceptado:08-05-2015

\section{Resumen}

En este artículo se caracteriza la naturaleza de la participación en los distintos niveles de territorialidad de la Agroecología como una "epistemología surgida de la praxis". La descripción de su construcción histórica en Latinoamérica permite conocer la evolución de dicha epistemología: desde sus orígenes campesino-indígenas, pasando por las etapas de hibridación tecnológica y socioeconómica. Donde se produce en forma participativa la articulación del conocimiento local con el científico-disidente al manejo industrializado. Hasta la última etapa de construcción participativa de propuestas de liberación sociocultural y política.

Palabras clave: agroecología, investigación-acción participativa, conocimientos local campesino e indígena. 


\title{
The Latinoamerican historical building of Agroecology and its territoriality levels
}

\begin{abstract}
In this article is characterized the nature of participation in the different levels of territoriality of Agroecology as one "epistemology rise from the praxis". The description of its historical construction in Latin America allows knowing the evolution of this epistemology: since its peasant-indigenous origins, passing through the stages of technological and socio-economic hybridization. Is here where participative-action produce a way of articulation between local knowledge and the scientific-dissidence from industrialized agriculture. The last stage is that of participatory construction of proposals of socio-cultural and political liberation.

Keywords: Agroecology; Participative-action Research; Local; Peasant and Indigenous Knowledge.

\section{Referencia normalizada}

Sevilla GuZmÁn, Eduardo (2015): “La participación en la construcción histórica latinoamericana de la Agroecología y sus niveles de territorialidad”, Política y Sociedad, 52 (2), pp. 351-370.

Sumario: 1.Introducción. 2.Sobre la génesis y evolución de la Agroecología. 3.Etapa de resistencia y construcción participativa campesino/indígena. 4.Etapa de hibridación tecnológica y propuesta socioeconómica. 5.Etapa de construcción de las Formas de Conciencia Agroecológicas como plataformas interculturales de sustentabilidad. 6.A modo de conclusión: la Agroecología como estrategia de construcción y liberación sociocultural y política desde sus niveles de territorialidad. 7.Bibliografía.
\end{abstract}




\section{Introducción}

Comprender la naturaleza de la participación en Agroecología requiere retrotraerse a su génesis y evolución histórica en Latino América. La Agroecología surgió a finales de los años setenta de la pasada centuria, como respuesta a las primeras manifestaciones de la crisis ecológica y social en el campo, generada por la intensificación del desarrollo del capitalismo en la agricultura; que extendía al conjunto del planeta el modelo de la revolución verde, basado en el manejo químico e industrializado de los recursos naturales. Las distintas formas de resistencia practicadas por grupos campesinos e indígenas generaron una dinámica de participativa que actuó como plataforma de enfrentamiento a la acción de las multinacionales; negándose a aceptar los paquetes de agroquímicos, vinculados a las semillas híbridas que destruían su manejo tradicional, deterioraban sus bienes comunales (aire, agua, tierra y biodiversidad); y atentaban contra sus identidades socioculturales introduciéndolas coactivamente en la Modernidad, a través de su mercado capitalista.

Fue así como surgieron los cimientos del edificio agroecológico, que fueron construidos desde la referida dinámica participativa, al verse reforzada por la interacción entre tales grupos de campesinos e indígenas con técnicos disidentes al manejo industrializado, una vez comprobado el deterioro ecológico que ello acarreaba. Como enfrentamiento a esta emergente industrialización agroalimentaria surgió una alianza campesino/indígena con la disidencia a tal agroindustialización capitalista cuyos modos de participación elaboraron una contundente respuesta. En ella se encontraba: no solo una rigurosa crítica al deterioro ecológico y sociocultural de aquel manejo industrial; sino, también y sobre todo, en la construcción de una sólida alternativa, que adoptó la denominación de Agroecología. Y que, como veremos más adelante, rebasó el ámbito del manejo medioambiental de los bienes ecológicos comunales (aire, agua, tierra y biodiversidad); para introducirse en la circulación de los productos; desafiando la hegemonía del sistema agroalimentario pretendiendo, revertir su naturaleza capitalista; mediante propuestas de transformación cultural y políticas.

Fue la nueva agricultura ecológica así configurada lo que provocó el "redescubrimiento" de la Agroecología, por parte de la Ciencia Agronómica, al restablecer la valoración de los conocimientos que atesoraban las culturas de los pueblos campesino e indígenas (de transmisión y conservación oral, sobre las interacciones que se producían entre la naturaleza y la sociedad) que la Modernidad había invisibilizado para establecer la hegemonía de su "ciencia". Fue esta práctica pluriepistemológica, utilizando metodologías participativas quien demostró la impotencia de la "ciencia convencional" para resolver los problemas ecológicos y medioambientales que la agricultura, ganadería y forestería industrializada generaba para su introducción al sistema agroalimentario global. Tal demostración surgió al denunciar la manipulación que se desarrollaba sobre el sistema de ciencia al verse sometido a la acción coactiva de las multinacionales agroalimentarias que actuaba como un elemento central en la estructura de poder de la Modernidad capitalista. 
A pesar de la acción de estos mecanismos de coacción institucional sobre las estructuras académicas de investigación y docencia, tratando de imponer a nivel mundial el modo industrial de uso de los recursos naturales; determinados núcleos de la "Academia" iniciaron procesos de investigación demostrando el deterioro medioambiental que ello comportaba.

Se produjo así una alternativa científica basada en la constatación empírica de que el conocimiento sobre el manejo de la naturaleza del pasado, e incluso el generado en las culturas marginadas por la civilización industrial, poseía los principios ecológicos que permitían evitar, no solo el deterioro medioambiental; sino también el social. En efecto, el conocimiento local, campesino y/o indígena de dichas tecnologías depende de valores insertos en matrices socioculturales de sus identidades que se enfrentan, normalmente a la lógica del lucro y, también, a la exclusión social de las tecnologías de matriz neoliberal. Fue así como, junto a la práctica de los agricultores y técnicos disidentes (al manejo industrial), se fueron construyendo participativamente reflexiones teóricas y avances epistemológicos hasta conseguir la aceptación de una necesaria complementariedad entre el conocimiento científico y la epistemología popular para resolver la trágica situación de confluencia global de las crisis ambiental, energética, alimentaria, sociocultural y económica; en definitiva: civilizatoria, que se generaba ya en aquel momento, y que sufrimos con fuerza en la actualidad (Altieri, 1985; Reijntjes et al., 1992; Funtowicz and Ravetz, 1994; Pretty, 1995; Gliessman, 1998;Guzmán Casado, G.et al., 2000; Sevilla Guzmán y Graham Woodgate, 1997-2002).

En las páginas que siguen vamos a presentar esquemáticamente: (a) en un primer apartado, los rasgos clave de la génesis y evolución de la agroecología; (b) en un segundo epígrafe, los modos participativos que desarrollaron los grupos campesinos e indígenas como resistencia intercultural a la penetración del dominio de las multinacionales en sus manejos de los bienes ecológico/comunales; (c) posteriormente me centraré en las metodologías participativas elaboradas conjuntamente con los técnicos de campo que apoyaban su lucha; y (d) finalmente, presentaré la estrategia actual de la Agroecología frente a la modernidad capitalista, explicitando su especificidad en los distintos niveles de territorialidad.

\section{Sobre la génesis y evolución de la Agroecología}

La Agroecología es una construcción popular, surgida de la alianza entre sectores campesinos e indígenas con técnicos (ecólogos, agrónomos, sociólogos y antropólogos) que, con diferente experiencia, vinculada al manejo de los bienes naturales y agrupados en $\mathrm{ONG}^{\prime} \mathrm{s}$; fue realizada en Latinoamérica, a través de una dinámica participativa en la que, a agrandes rasgos, pueden diferenciarse tres etapas. La primera se extiende a lo largo de los años 80's de la pasada centuria y se podría calificar como etapa de resis- 
tencia y construcción participativa campesino/indígena. En ella se produce el ajuste intercultural entre grupos campesinos e indígenas, que generaría una toma de conciencia y el posicionamiento político frente a las diferentes formas de agresión y exclusión social que establecían sobre ellas las multinacionales agroalimentarias; $y$, todo ello en un contexto de apoyo oficial por las políticas públicas internacionales.

La segunda es la etapa de hibridación tecnológica y propuesta socioeconómica, donde se consolida y formaliza el "diálogo de saberes", ya iniciado en la articulación campesino/indígena; y se construye una alternativa a la agricultura industrializada y su sistema agroalimentario global; ocupando temporalmente los últimos años de la primera etapa y la totalidad de la década de los 90's. La tercera etapa que, con unos límites flexibles, abarca la primera década del 2000; puede ser definida, como etapa de construcción participativa de propuestas de liberación sociocultural y política, por su articulación con los movimientos sociales y la generalizada aceptación académica. En ella se concluye una estrategia de construcción local de "alternativas al desarrollo" como transformaciones socioeconómicas y político culturales endógenas, que se consolidan como alternativas a la Modernidad capitalista; al tiempo que termina el abierto apoyo de las políticas internacionales a la agricultura industrializada, en una ambigua neutralidad.

El elemento clave generador de este proceso fue la dinámica participativa que se estableció entre los agentes participantes en el proceso. Primero, entre los grupos de resistencia campesino/indígena que contrastaban sus diferentes cosmovisiones para intercambiar el manejo conservacionista que desarrollaban sobre sus agroecosistemas, pretendiendo con ello complementar la parcialidad de sus epistemologías, como método para mejorar el potencial regenerativo de los mismos. Más tarde, la dinámica participativa se enriqueció con un nuevo agente: los técnicos disidentes al manejo agroindustrial unificador. Ello permitió elaborar, a través de metodologías participativas de análisis y diagnóstico, una estrategia de construcción epistemológicasurgida de una praxis que, iniciándose desde la agricultura, ganadería y forestería, alcanzó una forma de producir regenerativa, en lo ecológico. No obstante, al conseguir este logro se percibió la necesidad de ampliar su enfoque, mediante una concepción socioeconómica que, junto al proceso productivo, abarcara todo lo largo del proceso de circulación del producto hasta alcanzar al consumo. Fue así como se llegó a sentir una nueva necesidad: ampliar su alianza (hasta entonces de sectores campesino/indígena con técnicos alternativos) a otro sector social con el que interactuar: el de los ciudadanos que, militantemente, eligieran ser sus consumidores.

El hecho de que la alianza inicial campesino/indígena (de construcción epistemológica, basada en la praxis) se realizara mediante metodologías participativas para elaborar sus estrategias de resistencia supuso la articulación de tales modos participativos con aquellos que traían los técnicos disidentes, en la ampliación de su alianza, ensanchándose así la búsqueda: en el terreno de la producción de agriculturas de base ecológica; con la búsqueda, en el terreno de la circulación, de mercados alternativos 
que evitaran la extracción del excedente capitalista. La nueva ampliación de la alianza, introduciendo al consumidor buscando el apoyo militante de la ciudadanía, transformó al consumo en un acto político generador de una nueva dinámica de empoderamiento. El nuevo contexto de construcción epistemológico popular, introdujo a su vez un nuevo elemento, como consecuencia del incremento de la diversidad cultural y de la praxis adquirida en las dinámicas participativas donde se producía una demanda cada vez más pluriepistemológica.

Las nuevas metodologías participativas así generadas elaboraron un discurso: no ya de enfrentamiento a la agricultura industrializada y a su sistema agroalimentario; sino de elaboración de alternativas productivas con prácticas socioeconómicas y culturales (de generación de calidad de vida vinculada a mercados solidarios) con capacidad expansiva como para generar dinámicas de transformación sociopolíticas. Apareció así una estrategia de combate a los modos de ocultamiento de la realidad que la Modernidad capitalista despliega desde su estructura de poder contra aquellas formas de vida que escapan a su lógica de comprensión del mundo y que conseguían llegar a producir una falsa, pero efectiva, virtualidad de su no existencia (Santos, 2009: 100-110).

\section{Etapa de resistencia y construcción participativa campesino/indígena}

En lo que sigue vamos a mostrar cómo la reflexión campesino/indígena llega (aun sin el acompañamiento de los técnicos disidentes) a comprender que sus parcialidades socioculturales poseen un conocimiento cuya reflexión participativa desvela los modos de colonización que instrumentalizan ideológicamente su manejo de los bienes naturales pretendiendo con ello; no solo ocultarlos, sino crear sobre las parcialidades socioculturales que los producen, formas de no existencia excluyéndolas social, económica y políticamente de su participación en los distintos ámbitos de la sociedad.

Desde sus inicios, la Agroecología se ha ido conformando por iniciativas de determinados grupos campesinos e indígenas, en un proceso de acción social colectiva. Ello tuvo lugar a lo largo de los encuentros que, en distintos territorios latinoamericanos, fueron desarrollándose, desde el comienzo de los años ochenta. Lo iniciaron quienes se autodenominaban "sindicatos revolucionarios campesinos" mediante acciones de convergencia que luchaban por una reforma agraria y contra el acaparamiento de las tierras usurpadas a sus pares, que habían caído en la trampa de los agroquímicos y demás insumos externos, de naturaleza industrial; y habían visto destruidos sus sistemas territoriales de autosuficiencia agroalimentaria.

Desde los primeros encuentros y junto a las áreas de trabajo de carácter más político y reivindicativo, se fueron creando espacios que consolidaron una red de intercambio para el fortalecimiento del manejo de sus bienes ecológicos comunales (aire, agua, tierra y biodiversidad): proponiendo estrategias de recuperación de los manejos 
tradicionales "de campesino a campesino". La primera acción de este tipo en Latinoamérica, tuvo lugar en Managua en diciembre de 1981 en el marco de la Reunión Continental de Reforma Agraria y Movimientos Campesinos. Surge allí una interacción, que significaría el inicio de la configuración del Movimiento Continental Campesino y de los Pueblos Indígenas en Latinoamérica. En este proceso, diversas organizaciones latinoamericanas (con una pequeña representación europea) descubren la similitud tanto de sus formas de lucha como de su evolución ideológica. Esta tenía, en sus inicios, tenía una naturaleza ideológica rígidamente marxista y libertaria que evolucionó hacia formas que, sin abandonar el núcleo de tales ideas, aceptaran las cosmovisiones de las parcialidades socioculturales indígenas, en el contexto de una propuesta agroecológica liberadora (Sevilla Guzmán, 2006a).

Probablemente, el siguiente eslabón de este proceso de confluencia de organizaciones campesinas independientes fuera el que tuvo lugar los días 14 y 15 de noviembre de 1984. Entonces, y convocado por la Coordinadora Nacional Plan de Ayala de México, tuvo lugar el Encuentro Latinoamericano de Organizaciones Campesinas Independientes donde se intercambiaron experiencias entre la Confederación Campesina del Perú, la Federación Nacional de Organizaciones Campesinas del Ecuador, el Movimiento Campesino Independientes de República Dominicana, la Confederación Nacional de Sindicatos de Trabajadores Campesinos de Francia; el andaluz, Sindicato de Obreros del Campo; el Sindicato de Trabajadores Rurales y el recién constituido Movimiento de los Trabajadores Rurales sin Tierra de Brasil (MST). Otros espacios de confluencia en el proceso de disidencia lo constituyen los eventos de intercambio internacional convocados por el MST del Brasil en 1985 y por la FENOCI de Ecuador en 1986. En este último país se realizó en octubre de 1987 el Primer Taller Andino de Intercambio de Organizaciones Campesino-Indígenas; donde se realizó una primera sistematización de manejos y gestión campesino/indígena de los bienes naturales en los diferentes pisos ecológicos de sus territorios. En octubre de 1989, organizaciones indígenas y campesinas de la Región Andina y el MST del Brasil, llamaron a la Campaña Continental 500 Años de Resistencia Indígena, Negra y Popular en Bogotá, Colombia; realizándose tres Encuentros Continentales y varias reuniones de coordinación de diferentes países de América Latina y con la presencia de organizaciones rurales - autodenominadas campesinas - europeas (Sevilla Guzmán y Martínez Alier, 2006a: 472-483 y 2006b; Sevilla Guzmán, 2006a: 13y 14).

En tales encuentros, el conocimiento del manejo de los bienes comunales de las parcialidades culturales indígenas (algunas de ellas con cosmovisiones originarias) era confrontado con los correspondientes conocimientos campesinos, donde la erosión moderna había anulado prácticamente las cosmovisiones originarias en que sus ancestros basaron el manejo de sus bienes naturales. Es aquí donde se inicia el proceso de construcción del "dialogo de saberes": tanto desde el punto de vista de la socialización de formas de manejo agrosilvopastoril; como, desde la perspectiva de las metodologías 
participativas. Así, por ejemplo, los indígenas mexicanos (nahuas y guicholes, entre otros) y los andinos (quechuas y aymaras) confrontaron experiencias, con los campesinos del Chaco y la Mesopotamia argentina o con sus pares del Maule y la Araucanía chilena. Tales confrontaciones de intercambio se realizaban tanto respecto a los manejos tecnológicos tradicionales de sus bienes naturales, como respecto a la gestión agroalimentaria de sus territorios en mercados locales, con circuitos cortos, o ferias con distintos grados de territorialidad. Y de ellas salían sistematizaciones propias que, desde su forma de conocimiento, mostraban la racionalidad ecológica de su parcialidad sociocultural, respecto al manejo suelo, clima, vegetación, animales y, en general, ecosistemas. Ello se tradujo en la reafirmación de sus estrategias multidimensionales de producción (por ejemplo, ecosistemas diversificados con múltiples especies), con capacidades regenerativas (dentro de sus, endógenas y peculiarmente ecológicas, técnicas tradicionales) que conseguían la autosuficiencia alimentaria de sus familias y los habitantes de sus territorios.

En la segunda mitad de los años 80 's se da una clara coincidencia en diversos puntos de Latinoamérica. Por un lado, aparecen ya consolidadas un amplio número de estas iniciativas y experiencias campesino/indígenas; y por otro, comienzan a percibirse múltiples fracasos de proyectos de desarrollo rural realizados por ONGs y centros de capacitación. Ello lleva a muchos de sus técnicos a contactar con estas experiencias, intentando reconvertir sus proyectos introduciendo manejos endógenos campesino/indígenas de base ecológica, e incluso a independizarse de sus instituciones para unirse en procesos de acompañamiento a tales experiencias. Aparece, así, el rescate de tecnologías y saber local, campesino e indígena que es asumido como la hibridación tecnológica de la agroecología en el seno del Movimiento agroecológico Latinoamericano (MAELA), dentro de un proceso de toma de conciencia hacia una praxis intelectual y política de transformación social. Esta agrupación adoptó entre sus objetivos: "Contribuir con el proceso de cambios sociales, políticos y científico-tecnológicos, que conduzcan a la construcción de un nuevo modelo de desarrollo que sea socialmente justo, ecológicamente sustentable, económicamente viable, que respete la diversidad cultural y tenga una participación popular activa, en igualdad de condiciones y oportunidades entre hombres y mujeres" (MAELA, 2000: 78).Aunque esta agrupación estuviese vinculada en su origen a la Federación Internacional de Movimientos de Agricultura Orgánica (IFOAM), la especificidad de la agroecología campesino/indígena de Latinoamérica generó un proceso de alejamiento, que cristalizó en una escisión institucional, al producirse la regionalización que realizó IFOAM, en Cochabamba, Bolivia, en 1989.

Agricultores y campesinos, pertenecientes a las referidas experiencias en Argentina, Brasil, Bolivia, México, Chile y Colombia, se reunieron en diciembre de 1998 en un lugar de este último país, Pereira, estableciendo una declaración de principios, como miembros del Movimiento Agroecológico de América Latina y el Caribe (MAELA), en la que expresaban su "oposición al modelo neoliberal... por degradar la naturaleza y la 
sociedad. Al mismo tiempo, establecían como un derecho de sus organizaciones locales la "gestión y el control de los recursos naturales... sin depender de insumos externos (agroquímicos y transgénicos), para la reproducción biológica de sus culturas", señalando su "apoyo a la promoción, el intercambio y difusión de experiencias locales de resistencia civil y la creación de alternativas de uso y conservación de variedades locales" (MAELA, 2000). Expresaron también en aquel manifiesto, de claro contenido político, su "solidaridad con el movimiento Sin Tierra del Brasil, los movimientos campesinos de Bolivia, los indígenas Mapuches de Chile, los campesinos indígenas de Chiapas", entre otros grupos, como una muestra de internacionalismo campesino agroecológico.

\section{Etapa de hibridación tecnológica y propuesta socioeconómica}

Esta etapa requiere que se haya producido el encuentro de la referidas experiencias campesino/indígenas con los técnicos, disidentes del manejo de naturaleza industrial. Son muchas las formas de encuentro como posible inicio de tal interacción (que normalmente surge como demanda campesina y/o indígena, o circunstancia análoga) que generó el contacto entre las dos formas de conocimiento: tradicional — portador de los manejos de las diferentes parcialidades campesinas e indígenas - y alternativo/moderno con contenidos del "manejo orgánico moderno". Se produjo, así, el contexto para que se realizara la ampliación de la construcción colectiva de conocimiento dentro de: por un lado, el diálogo de saberes; y por otro, los procesos participativos de autodiagnóstico y análisis ya iniciados en la etapa anterior.

Fue de esta forma como floreció, poco a poco, la investigación acción participativa de la agroecología. La mayor dificultad procedía de la naturaleza de las interacciones que propicia el comienzo de metodologías participativas entre las distintas parcialidades socioculturales. El mutuo conocimiento, profundo, hasta conseguir la obtención de una relación horizontal, resulta imprescindible para el desencadenamiento de las acciones encaminadas al empoderamiento que permita la relación simétrica entre las dos partes; sin la cual la acción crítica y subversiva, de naturaleza agroecológica, no se produce.

Junto a la prevalencia del conocimiento campesino/indígena en la hibridación agropecuaria y forestal del diálogo de saberes fue forjándose la prevalencia moderno/ alternativo del conocimiento de los técnicos disidentes en la hibridación metodológica. Así, la agricultura de base ecológica de la agroecología aparece de la concepción holística del ecosistema que posee la mirada campesino/indígena, en la que la fertilidad natural del suelo es potenciada mediante los aportes orgánicos de la flora y fauna circundante desde los manejos de los insumos localmente accesibles que permiten un cultivo basado en la búsqueda del incremento de la biodiversidad y de la aportación de nutrientes de las interacciones de las rotaciones prediales. De igual forma, la investigación acción participativa de la agroecología se fue desarrollando 
mediante el enriquecimiento de los espacios de reflexión análisis y autodiagnóstico campesino/indígena con los aportes de los nuevos actores en sus encuentros en común, que introducían elementos técnicos de planificación, participación y sociopraxis, buscando obtener una mayor implicación crítica de los participantes. Los marcos teóricos y enfoques de intervención metodológicos, con los que iniciaron tales procesos de acompañamiento, fueron los de Paulo Freire (1969-1982) y Orlando Fals Borda (1964, 1991; Fals Borda, R. Villasante et al. 1993) sobre la investigación participativa para la liberación socioeconómica y política del oprimido, que fueron paulatinamente adaptándose al contexto agropecuario y forestal en que se realizaban sus luchas. Esta filosofía política inicial permitió un desarrollo teórico académico con la incorporación de los técnicos acompañantes de las experiencias campesino/indígenas a programas de investigación: "donde su investigación/militante, por un lado y la investigación participativa, por otro se articuló con los movimientos sociales y, el desarrollo de tecnologías en finca, acabó constituyendo nuestro encuentro con la agroecología" (Sevilla Guzmán, 2006a: 147-150 y 11-22).

De esta forma se consolidaron los marcos teóricos de la agroecología, que, en lo esencial pienso, pueden mostrarse siguiendo los títulos de sus autores más destacados. La sucesión de los mismos sería la siguiente: la agroecología surge de un "Ecologismo de los pobres" (Martínez Alier, 2005) que, sintió la necesidad de "Estudiar la agricultura tradicional"(Altieri, 1991); para, desde ella, desvelar "Las raices económicas del deterioro ecológico y social (Naredo, 2006); buscando las "Bases científicas para una agricultura sustentable" (Altieri, 1999); para "Entendiendo los procesos ecológicos de una agricultura sustentable"(Gliessman, 1997-2002); pasar "Desde la agricultura industrializada a la agroecología" (Sevilla Guzmán y Graham Woodgate, 19972002); construyendo "Redes agroalimentarias, desde una perspectiva agroecológica una Nueva Cuestión Agraria, como respuesta a la globalización económica" (Woodgate, et. al, 1999-2005: 586- 612); incorporando las conceptualizaciones campesino/ indígenas, al transitar "Del desarrollo local a las redes para el Buen Vivir" (R. Villasante, 1998) e incorporar, a las "Luchas indígenas su modernidad alternativa" (Toledo, 2000), construida agroecológicamente desde cada parcialidad sociocultural; articulada con los: "Nuevos movimientos sociales y agroecología" (Sevilla Guzmán y Martínez Alier, 2006a).

Fue así como se inició un proceso de agroecologización de los movimientos rurales en Latinoamérica. Aunque es obligado reconocer aquí que tal fenómeno se inició en Brasil, donde, desde mitad de los años noventa, el CETAP (Centro de Tecnologías alternativas Populares) fue creado para iniciar un proceso de articulación de las experiencias agroecológicas de los siguientes movimientos sociales agrarios de Rio Grande do Sul: MAB (Desplazados por las presas — barragens-), MMTR (Movimiento de mujeres trabajadoras rurales), MST (Movimiento de los sin tierra) y MPA (Movimiento de pequeños agricultores). 


\section{Etapa de construcción de las Formas de Conciencia Agroecológicas como plataformas interculturales de sustentabilidad}

La agroecología desarrolla el conjunto de acciones hasta ahora reseñadas en tres diferentes dimensiones: una primer dimensión ecológico/productivo que se inicia en el nivel predial, donde, en la propia dinámica del desarrollo participativo de tecnologías en finca, comienza una la estrategia de denuncia y lucha contra los transgénicos y demás agentes del deterioro. Esta degradación se produce: tanto a la naturaleza (degradación física y biológica del suelo por pérdida de nutrientes; polución y demás formas de degradación atmosférica; contaminación de agua y efectos en recursos genéticos y vida salvaje); como a las personas: por un lado, mediante la ingestión y/o polución de alimentos químicamente contaminados; y por otro, a través de la acción degradante sobre la vida humana que supone el transformar la comida en mercancía sometida a la lógica del lucro que domina el mercado capitalista.

Una segunda dimensión socioeconómica adiciona a los manejos ecológicos la articulación de experiencias productivas para utilizar los mercados locales y ferias comarcales o, incluso, generar mercados alternativos barriales, buscando una acción social colectiva que amplíe su campo de la esfera de la producción a la de la circulación; donde se continúa y profundiza la estrategia de denuncia y construcción de alternativas, elaborada desde sus diagnósticos participativos y sus talleres de reflexión y articulación.

Dese estos espacios de reflexión construidos, con la aparición de $\mathrm{ONG}^{\prime}$ s (como PRATEC 1-/ en Perú y AGRUCO, en Bolivia; o CLADES, esparcida por gran parte del territorio latinoamericano) en la dinámica de encuentro y confluencia campesino/indígena caracterizada en la etapa anterior, se construyó una estrategia de devolución de visibilidad a los parcialidades socioculturales científicamente ocultadas: no solo al denunciar desde el manejo andino, amazónico, chaqueño o mesopotámico de sus bienes naturales la depredación sociocultural que sobre ellos se desarrollaba, sino al presentar herramientas de emancipación contra la estructura de poder de la modernización occidental.

Fue así como aparecieron las alternativas de liberación y combate a la modernidad capitalista que fueron denominadas como "las formas de conciencia" al accionar a través de una actividad transformadora en distintos espacios sociales para conseguir su liberación de la no existencia que sobre ellos genera la Modernidad capitalista. Son éstas, la conciencia de especie (frente a la explotación ecológica intergeneracional o, en otra palabras; los bienes naturales no son la herencia a nuestros hijos, sino el préstamo de nuestros nietos), la conciencia de clase (frente a la explotación económica intrageneracional que, a través de la extracción del excedente, genera el mercado capitalista), conciencia de identidad (frente a la discriminación y demás formas de explotación étnica), conciencia de género (frente a la discriminación de mujer y demás modos de explotación vinculados al género) y la conciencia de explotación generacional (de una a otra generación; como son la discriminación de los mayores y la explotación 
económica y marginación de los niños de la calle). Estas formas de conciencia agroecológica actúan como plataformas interculturales de sustentabilidad en forma acumulativa en las dos primeras dimensiones (ecológico/productiva y socio-económica) en que se mueve la agroecología, para desarrollar su plenitud en la tercera dimensión sociocultural y política, que pasamos a considerar.

Como hemos adelantado, las formas de conciencia agroecológica son el resultado acumulativo de las estrategias de rescate, elaboradas conjuntamente por las parcialidades culturales involucradas en la acción de las dos perspectivas (ecológico/productiva y socioeconómica) hasta ahora consideradas, que al actuar en el campo, o perspectiva, sociocultural y político se transforman en Plataformas Interculturales de Sustentabilidad. Su acción liberadora se desarrolla organizado las distintas formas de resistencia; los espacios de diagnóstico y reflexión; y las estrategias de liberación para elaborar las acciones de enfrentamiento al capitalismo; como alternativas a la forma de vida de su Modernidad. Ello se lleva a cabo a través de una metodología participativa de discusión y argumentación entre las propias parcialidades socioculturales con experiencias agroecológicas ocultadas respecto a las hegemónicas; generando así una disputa holística desde la interculturalidad. De esta forma, se consigue que, desde sus propias experiencias agroecológicas, las parcialidades socioculturales de las que surgen (al liberarse de las relaciones de producción capitalistas y los modos de ocultación modernos, a ellas vinculados) alcancen tornarse como presentes. Consiguen, de esta manera, hacerse visibles (mediante la obtención de su consideración como alternativas reales) a las experiencias hegemónicas del campo socioeconómico en que se mueva

Boaventura de Sousa Santos (2009: 110-112) llama a este tipo de acciones, que realiza la Agroecología, crear las condiciones que permiten "ampliar el campo de las experiencias creibles en este mundo y en este tiempo y, por tal razón, se contribuye a ampliar el mundo y a dilatar el presente", dentro de su estrategia de devolución de visibilidad. Esta pasa, en primer lugar, por identificar los ámbitos de sustracción y contracción del mundo en que actúa la Modernidad capitalista; y que vienen definidos por cinco manifestaciones de su racionalidad, que Santos denomina monoculturas de la mente: del saber y del rigor del saber; del tiempo lineal; de la naturalización de la diferencia jerárquica; universalista y globalizadora; y la monocultura del productivismo. La acción como plataformas de sustentabilidad de las formas de conciencia agroecológica, que acabamos de caracterizar, es definida por Santos (2009: 114-131) a través de cinco ecologías como formas de superación de la invisibilidad: ecología de los saberes; de las temporalidades; de los reconocimientos; de lastransescalas; y de las productividades.

Como he demostrado en otro lugar (Sevilla Guzmán, 2011: 13-41) la investigación La Reinvención de la emancipación social, que Boaventura de Sousa Santos desarrollo de 1999 a 2002 poseía una clara similitud con el proceso de génesis y evolución de la Agroecología hasta aquí caracterizado. Los grupos campesinos e indígenas generadores poseían otros discursos o narrativas sobre el mundo, alejados de los centros de 
producción de la ciencia social y buscaban una independencia de las concepciones hegemónicas respecto a su gestación. Igualmente sus discursos se encuentran en general, dentro de culturas diferentes y subculturas insertas en el terreno de las luchas, iniciativas, movimientos alternativos, muchos de ellos locales, muchas veces procedentes de lugares remotos del mundo. Más aún, la acción agroecológica persigue determinar en qué medida la globalización alternativa podría ser producida desde abajo y cuáles son sus límites y posibilidades. Desde el manejo de los bienes ecológicos comunales la Agroecología trabaja en sus diferentes niveles de territorialidad para constituirse en una alternativa creíble al capitalismo (Santos, 2009: 98 y 99).

\section{A modo de conclusión:}

\section{la Agroecología como estrategia de construcción} y liberación sociocultural y política desde sus niveles de territorialidad

Recordemos que la Agroecología puede definirse como (i) la búsqueda de un manejo ecológico de los bienes naturales para, (ii) mediante acciones locales endógenas, de naturaleza socioeconómica, construir sistemas agroalimentario locales, y (iii) generar procesos de transformación y sustentabilidad entre productores y consumidores. (iv) $\mathrm{Su}$ acción se articulada con los movimientos sociales (que se enfrentan al neoliberalismo y la globalización económica capitalista) para generar procesos de desmercantilización y democratización del conocimiento; (v) se pretende así incorporar, a las parcialidades socioculturales ocultadas, en plataformas interculturales de sustentabilidad; (vi) para elaborar participativamente procesos de transición agroecológica que permitan la emancipación y liberación sociocultural y política de la concepción del mundo de la modernidad capitalista. Veamos este proceso desde los distintos niveles de territorialidad.

\subsection{Nivel de territorialidad predial}

La agroecología se mueve en el nivel de territorialidad predial utilizando como metodología dominante, aunque combinada con otras muchas, el desarrollo participativo de tecnologías en finca; ya que ésta es la herramienta central de la hibridación tecnológi$c a$, entre los conocimientos local campesino y/o indígena; y el científico. Se obtiene así el manejo agroecológico predial, que rompe "empíricamente la ocultación moderna" de la superioridad de la agricultura orgánica sobre la de naturaleza industrial; cuando, en realidad en el contexto agroecológico, tal superioridad no solo tiene una naturaleza ecológica; sino que se torna, además económica, en términos de salud; y sobre todo desde un punto de vista ético. Al tiempo, se genera un contexto de reflexividad, que introduce elementos, socioeconómicos, culturales y políticos de la parcialidad subalterna en que nos movamos; de naturaleza expansiva al resto de los niveles de territorialidad. 
En efecto, en el nivel predial se inician los diagnósticos participativos, como metodología trasversal de análisis comunitario de la situación de la identidad sociocultural subalterna. Con ello se elaboran las estrategias de democratización del conocimiento, socialmente construido, mediante su desmercantilización. La primera acción agroecológica de esta naturaleza necesariamente consistirá en la desmercantilización de las semillas, seriamente amenazada desde el neoliberalismo de las organizaciones internacionales; donde prevalecen los intereses de la multinacionales agroalimentarias.

\subsection{Nivel de territorialidad comunal}

En este nivel de territorialidad local se da una clara prevalencia de la dimensión socioeconómica de la Agroecología, al actuar desde los procesos de circulación; pretendiendo como primera acción agroecológica, crear mercados alternativos como respuestas endógenas que eviten la extracción del excedente. Cuando la estrategia de democratización del conocimiento, iniciada en el nivel predial, se dirige a los consumidores en busca de una prevalencia de los valores de uso sobre los de cambio, para evitar la extracción capitalista, aparecen los mercados alternativos desde la Economía Solidaria. Tal acción se completa con la utilización de canales cortos orientados a los mercados locales; donde el reparto del valor añadido se realice básicamente entre el agricultor y el consumidor. Ello se consigue mediante la creación de asociaciones de productores y consumidores de naturaleza agroecológica; desde donde se realizan los diagnósticos participativos generando estrategias, en la identidad sociocultural subalterna, de democratización del conocimiento, socialmente construido, mediante su desmercantilización.

El nivel de comunidad local se desarrolla en una unidad espacial integrada por el conjunto de experiencias productivas y el conjunto de consumidores asociados en las organizaciones agroecológicas que han generado los distintos mercados alternativos existentes. Habrá pues, tantos mercados alternativos en la comunidad local en que nos encontremos como asociaciones de productores-consumidores de las que surgen. La articulación de tales mercados alternativos dotará a la entidad de población en se produce tal articulación de una heterogeneidad sociocultural de acuerdo con la diversidad de las parcialidades subordinadas existentes. Si se produce un ajuste adecuado entre las plataformas de sustentabilidad de las distintas experiencias agroecológicas aparecerá un fuerte potencial respecto a la posible creación de instituciones económicas nuevas, ajenas a la racionalidad capitalista.

\subsection{La territorialidad en la sociedad local}

El nivel de territorialidad de la sociedad local está integrado por el conjunto de comunidades locales con algún tipo de adscripción histórica que establezca cierto grado de identidad; aunque a veces las delimitaciones administrativas otorguen mayor operati- 
vidad. Es este el nivel de territorialidad donde se diseñan normalmente los procesos de transición agroecológica tal como han sido caracterizados anteriormente. Lo ideal será hacer converger las articulaciones de las distintas experiencias agroecológicas existentes en las diferentes comunidades de la territorialidad en que actuemos. Agroecológicamente la territorialidad es más evidente, en este nivel, cuanto más fuerte sea la visibilidad de su parcialidad sociocultural, como es el caso ce los puebles indígenas, y más aún si éstos conservan su cosmovisión como pautadora de su manejo originario de los recursos naturales. Aunque en los procesos de transición, a nivel de sociedad local, se utilizan todo el conjunto de herramientas participativas que hemos ido caracterizando; creemos importante recordar que todas ellas se inscriben en la dinámica de la técnica agroecológica central: la investigación/acción participativa como mecanismo de ruptura de la relación científica sujeto-objeto. Esto implica, una transformación radical en el sujeto científico; antes concebido como un observador neutral, objetivo y externo a la realidad que escruta y en la que el investigador no puede intervenir. Por el contrario, el antiguo objeto que había de ser transformado; ahora es un sujeto que pertenece a la naturaleza a la cual observa y procura caracterizar y explicar para transformarla. De esta forma el (antiguo) sujeto, que actuaba como observador "universal" se transforma en (nuevo e incompleto) sujeto que actúa como investigador "situado", en un contexto de reflexividad.

La reflexividad del proceso de investigación consiste en aceptar que la realidad no es sólo una estructura definida, sino también es producto y componente de una dinámica de estructuración del propio conocimiento; así la realidad se constituye y modifica por acción de la interacción sujeto-objeto. O dicho en otras palabras, la teoría en el mismo proceso cognoscitivo transforma el papel del sujeto en la construcción del conocimiento en su "objeto modificador". En efecto, el sujeto está inmerso en la realidad que conceptualiza creando lenguajes simbólicos particulares de esa realidad, es decir su rol es activo, creador y transformador de lo real. Por tanto, solo a través de la investigación/acción participativa el rol del investigador será resituado en el contexto adecuado a las demandas de la identidad sociocultural en proceso de intervención para el desarrollo. Solo desde esta perspectiva es posible definir los procesos tecnológicos desde su reflexividad sociocultural real. Así, el desarrollo de tecnologías en finca (hibridación tecnológica), los diagnósticos participativos (creación de estrategias), como metodología agroecológicas asentadas en los niveles predial y de comunidad local, necesitan de un curso dinámico para la consolidación del desarrollo endógeno (surgido desde dentro) que solo adquiere su plena eficacia a través de la investigación/acción participativa. Si ello tiene lugar mediante la interacción de la parcialidad moderna desprovista de sus "históricas monoculturas de la mente" y una parcialidad sociocultural originaria la probabilidad de obtener una autentica coproducción de conocimiento se multiplica. 


\subsection{Nivel de territorialidad estatal}

El nivel de territorialidad estatal de la Agroecología se mueve en la dimensión política, al actuar generando procesos de articulación entre los distintos conjuntos de acción agroecológica y los movimientos sociales de disidencia al neoliberalismo y la globalización existentes en esta territorialidad. Aquí la estrategia de democratización del conocimiento se dirige no solo a las parcialidades socioculturales subordinadas, sino al conjunto de la sociedad ya que lo que se pretende es incidir participativamente en la generación de políticas públicas. Ello requiere un abordaje integral de los procesos implicados en una estrategia que abarque a la totalidad de los territorios y cuyo objetivo último sea facilitar procesos de transición agroecológica para obtener la sustentabili$d a d$. La acción agroecológica habrá de ir dirigida a: por un lado, a los actores sociales involucrados en los procesos de producción, circulación y consumo agroecológicos, y por el otro, a las diferentes instituciones públicas y de la sociedad civil en sus distintos niveles de intervención territorial. Se pretende así involucrar a todos los actores en procesos amplios de planificación participativa de la transición agroecológica hacia un desarrollo sustentable que produzca la acción transformadora deseada. Se persigue así ensanchar la esfera de lo público creando plataformas de sustentabilidad social que abran procesos que permitan incidir participativamente en la generación de políticas públicas. La Agroecología demanda del Estado un rol clave como garante al acceso universal al conocimiento de toda la población y como mediador entre los intereses públicos y los intereses mercantiles.

\subsection{Nivel de territorialidad global}

El nivel de territorialidad global aparece como articulación de los movimientos sociales vinculados al manejo de los recursos naturales, a comienzo de la última década de la pasada centuria. Aunque su gestación responde a contenidos históricos de luchas emancipatorias agrarias muy anteriores, fue en 1993 cuando se crea formalmente la Vía Campesina, como internacional de movimientos sociales agrarios; ésta ha de entenderse como resultado del proceso de articulación mundial de la disidencia al neoliberalismo y la globalización económica (Sevilla Guzmán y Martínez Alier, 2006). En el contexto de sus múltiples y periódicas reuniones, adoptaron la Agroecología como matriz tecnológica para su manejo de los recursos naturales, desarrollando un proceso de integración de propuestas en los espacios de debate y reflexión para alcanzar consensos que cristalizó en la formulación del concepto de soberanía alimentaria como el derecho de los pueblos a definir sus propias políticas sustentables de producción, distribución y consumo de alimentos, garantizando el derecho a la alimentación para toda la población, con base en la pequeña y mediana producción, respetando sus propias culturas y la diversidad de los modos campesinos, pesqueros e indígenas de producción y comercialización agropecuaria, y de gestión de los espacios rurales. Desde la territorialidad global la estrategia 
agroecológica se torna en la búsqueda de una transformación política socioambiental, marcándose como objetivo la obtención de la Soberanía Alimentaria. Aquí la estrategia de la agroecología se centra en identificar los ámbitos de sustracción y contracción del mundo para desvelas la ocultación que la modernidad desarrolla sobre las experiencias alternativas que democratizan el conocimiento y desmercantilizan los bienes ecológicos comunales. Se trata de articular las diferentes experiencias agroecologías existentes en los distintos niveles de territorialidad para la recreación de distintos modos de confrontación a la "ocultación moderna" superando la invisibilidad por ella creada. Esta acción agroecológica de la Vía Campesina es desarrollada por el conjunto de actores sociales que, desde el manejo de los recursos naturales, utilizan las respuestas endógenas desarrolladas desde sus diferentes parcialidades socioculturales desplegando las potencialidades de sus identidades hacia una soberanía alimentaria.

\section{Bibliografía.}

Altieri, Miguel A., (1985): Agroecología. Bases Cientificas de la Agricultura Alternativa, Valparaíso, CETAL. Hay edición inglesa en (Boulder: Westeview Press, 1987)

Altieri, Miguel A., (1990): Agroecology and Small Farm Development, Ann Arbor, CRC Press.

Altieri, Miguel A., (1991): “¿Por qué estudiar la agricultura tradicional?”, en Agroecología y Desarrollo CLADES, 1, pp. 16-24.

Altieri, Miguel A., (1999): Agroecología. Bases científicas para una agricultura sustentable, Montevideo, Nordan-Comunidada.

Caporal, Francisco R. y José A. Costabeber (1998): La extensión agraria del sector público ante los desafios del desarrollo sostenible: el caso de Rio Grande do Sul, Brasil, Tesis Doctoral, Córdoba, 1998. 517p. Programa de Doctorado en Agroecología, Campesinado e Historia, ISEC-ETSIAN, Universidad de Córdoba, España.

Caporal, Francisco R. y José A. Costabeber (2000): “Agroecologia e Desenvolvimento Rural Sustentável: Perspectivas para uma Nova Extensão Rural. Porto Alegre" EMATER/RS, Revista Agroecologia e Desenvolvimento Rural Sustentável, Porto Alegre, EMATER/RS, 1 (1), jan/março, pp.16-37.

CAPoral, Francisco R. y José A. Costabeber (2001): "Agroecologia e desenvolvimento rural sustentável: perspectivas para uma nova Extensão Rural”, en Etges, Virgínia Elisabeta (org.) Desenvolvimento rural: potencialidades em questão, Santa Cruz do Sul: EDUSC, pp.19-52.

CAPoral, Francisco R. (2002): Recolocando as coisas nos seus devidos lugares: Um manifesto em defesa da Extensão Rural pública e gratuita para a agricultura familiar, Porto Alegre, EMATER/RS-ASCAR, Série Textos Selecionados, 24.

CAPORAL, Francisco R. y Paulo Petersen (2012): “Agroecologia e políticas públicas na América Latina: o caso do Brasil”, Agroecología Revista de la Universidad de Murcia, 69. 
Desmarais, Annette A. (2007): La Vía campesina: la globalización y el poder del campesinado, Madrid, Editorial Popular.

FALs, Orlando (1964): Estudios de la realidad campesina. Cooperación y cambio, Geneva, United Nations Rechearch Institute for Social Development.

FALs, Orlando (1991): “Algunos ingredientes básicos”. En: Acción y Conocimiento. Cómo romper el monopolio con investigación-acción participativa, Santafé de Bogotá, CINEP.

Freire, Paulo (1969-1982): Extensao ou Comunicaçao. Paz e Terra. Rio de Janeiro. La primera edición en castellano es de 1969: ¿Extensión o Comunicación?, Santiago de Chile, Instituto de Capacitación e Investigación en Reforma Agraria.

Funtowicz, Silvio and Jerome Ravetz (1994): Epistemología Política: ciencia con la gente, Buenos Aires, Centro editor de América Latina.

Gliessman, Stephen R. (1998-2002): Agroecology Ecological Processes in Sustainable Agriculture, Chelsea, Ann Arbor Press.

Guzmán, Gloria.; Manuel González y Eduardo Sevilla (2000): Introducción a la Agroecología como desarrollo rural sostenible, Madrid, Mundi-Prensa.

MAELA (2000): Perspectivas del movimiento agroecológico latinoamericano en el nuevo milenio, Cochabamba, Agruco, Editorial Poligraf.

Martinez, Juan (1987): Ecological Economics, Basil Blackwell, Oxford.

MarTínez, Juan (1998): La economía ecológica como ecología humana, Madrid, Fundación César Manrique.

MARTínez, Juan (1999): Introducción a la economía ecológica, Barcelona, Rubes editorial.

Martínez, Juan y Jordi Roca Jusmet (2000): Economía Ecológica y Política Ambiental, México, FCE/PNUMA.

MARTínez, Juan (2005): El ecologismo de los pobres, Barcelona, Icaria.

Martínez, Juan y Inge Ropke (2008): Recent Developments in Ecological Economics, Northamton, Edward Elgar, 2 vols.

Morales Jaime; y Jorge E. Rocha (eds.) (2006): Sustentabilidad Rural y Desarrollo Local en el sur de Jalisco, Guadalajara, Mexico, ITESO.

Morin, Edgar (1977): La Méthode: La Nature de la Nature, Paris, Éditions du Seuil, Tome I.

Morin, Edgar (1980): La Méthode: La Vie de la Vie, París, Éditions du Seuil, Tome II.

Morin, Edgar (1986): La Methodé: La Connaissance de la Connaissance, Paris, Éditions du Seuil, Tome III.

Mussoi, Eros M. (2008): "Extensão Rural: entre o ideal e o possível- uma abordagem comparativa a partir de duas experiências nacionais", en R.D. Thornton y G. Cimadevilla (eds.) Grises de La Extensión, la Comunicación y el Desarrollo, Buenos Aires, INTAInstituto Nacional de Tecnología Agropecuaria, pp. 199-223. 
NAREdo, José M., (1987): La economía en evolución, Madrid, Siglo XXI.

NARedo, José M., (2006): Raíces económicas del deterioro económico y social. Más allá de los dogmas, Madrid, Siglo XXI.

NorgaARD, Rirchard B. (1987): "The epistemological basis og agroecology". En Altieri, M.A. Agroecology, Westview Press, Boulder, IT Publications.

Norgand, Richard B. (1994): Development Betrayed: The End of Progress and a Coevolutionary Revisioning of the Future, London, Routledge.

Ottmann, Graciela (2005): Agroecología y sociología histórica desde Latinoamérica, Madrid/Córdoba/México, Mundi-Prensa/UCO/PNUMA.

Perez-Vitoria, Silvia y Sevilla Guzmán, Eduardo (2008): Petit précis d'Agroecologie. Nourriture, autonomie, paysannerie, Loriol, La Ligne d'Horizon.

Petersen, Paulo (ed) (2009): Agricultura Familiar Camponesa na construçao do futuro, Rio de Janeiro, AS-PTA, Brasil.

Ploeg, Jean D. van der y MARsden, Terry (2008): Unfolding webs: the dynamics of regional rural development. European Perspective on rural Development, Assen, Van Gorcum.

Ploeg, Jean D. van der, (2008): The New Peasantries, struggles for autonomy and sustainability in an era of empire and globalization, Londres, Earthscan.

Ploeg, Jean D. van der et al. (2006): “Dealing with novelties: a grassland experiment reconsidered” Journal of Environmental Policy and Planning 8 (3), pp. 199-218.

Ploeg, Jean D. van der, (2006): “Agricultural Production in Crisis", en P. Cloke, T. Marsden y P. Mooney, Handbook of Rural Studies, Londres, SAGE, pp. 258-277.

Pretty, Jules (1995): Regenerated Agriculture, Londres, National Academy Press.

Reijntjes, Coen, Bertus Harverkort y Ann Bayes (1992): Farming for the Future. An Introduction to Low-External-Imputs and Sustainable Agriculture, Londres, McMillan.

Rist Stephan, Mani Chiddambaranathan, César Escobar y Urs Wiesmann (2006): “It was hard to come to mutual understanding..." Multidimensionality of social learning processes in natural resource use in India, Africa and Latin America", Journal of Systemic Practice and Action Research, 19, pp. 219-237.

R. Villasante, Tomás, (1998): Cuatro redes para mejor-vivir, Buenos Aires, Lumen-Humanitas. 2 tomos.

R. Villasante, Tomás et al. (2001a): Prácticas locales de creatividad social, Madrid, Viejo Topo.

R. Villasante, Tomás et al. (2001b): La investigación social participativa, Madrid, Viejo Topo.

R. ViLlasante, Tomás (2006): Desbordes creativos. Estilos y estrategias para la transformación social, Barcelona, Viejo Topo.

SAntos, Boaventura de Sousa (2003): Crítica de la razón indolente. Contra el desperdicio de la experiencia, Bilbao, Desdée de Brouwer. 
Santos, Boaventura de Sousa (2009): Una epistemología del sur, México, Siglo XXI.

Sevilla Guzmán, Eduardo y Manuel L. GonzÁlez (1993): Ecología, campesinado e historia, Madrid, La Piqueta.

Sevilla Guzmán, Eduardo y Graha Woodgate (1997-2002): "Desarrollo rural sostenible: de la agricultura industrial a la agroecología", en Michael Redclift and Graham Woodgate (eds) Sociología del medio ambiente, Madrid, McGraw Hill. Traducción de la versión inglesa de 1997 con el título de Internacional Handbook on Environmental Sociology (Cheltenham,UK: Edgard Elgar).

SEvilla, Eduardo y Juan Martínez (2006): "New rural social movements and Agroecology", en P. Cloke, Terry Marsden y P.Mooney (eds.), Handbook of Rural Studies, London, SAGE Publications, pp. 472-483.

SEvilla, Eduardo (2011): Sobre los orígenes de la agroecología en el pensamiento marxista y libertario, La Paz-Bolivia, Agruco/ Plural Editores/ Center for Development ans Environment/NCCR.

Sevilla, Eduardo (2013): "Para Horacio Martins de Carvalho: una interpretación de la génesis y evolución de la agroecología como estrategia de emancipación social frente a la concepción occidental del mundo de la modernidad capitalista” ,en Horacio Martins de Carvalho, Agricultura familiar y el campesinado en América Latina, Montevideo, Creative Commons/Universidad de la República.

Toledo, Víctor M., (2000): La Paz en Chiapas, México, Ediciones Quinto Sol.

Toledo, Víctor M. (2012): "La Agroecología en Latinoamérica: Tres revoluciones, una misma transformación", Agroecología (Revista de la Universidad de Murcia, 68, pp. 37-47

TRICHES, Rozane M. y Segundo SCHNEIDER (2010): “Alimentação escolar e agricultura familiar: reconectando o consumo à produção", Saúde Sociedade, São Paulo, 4, pp. 933-945

Woodgate, Graham, Bianca Ambrose, Ramón Fernandez, Gloria Guzmán y Eduardo Sevilla (1999-2005): "Alternative Food and Agriculture Networks: An Agroecological Perspective on Responses to Economic Globalization and the New Agrarian Question", en Michael R. Redclift y Graham Woodgate (eds.), New Developments in Environmental Sociology, Cheltenham, U. K., An Elgar Reference Collection, MGP Books Ltd. pp. 586-612. 